\title{
Conservation of Quiver Trees in Namibia and South Africa under a Changing Climate
}

\author{
Danni Guo¹, Judith L. Arnolds', Guy F. Midgley², Wendy B. Foden ${ }^{3}$ \\ ${ }^{1}$ South African National Biodiversity Institute, Kirstenbosch Research Center, Claremont, South Africa \\ ${ }^{2}$ Department of Botany and Zoology, Stellenbosch University, Cape Town, South Africa \\ ${ }^{3}$ IUCN SSC Climate Change Specialist Group, Stellenbosch University, Cape Town, South Africa \\ Email: d.guo@sanbi.org.za, j.arnolds@sanbi.org.za,gfmidgley@sun.ac.za, fodenw@gmail.com
}

Received 12 May 2016; accepted 18 July 2016; published 21 July 2016

\begin{abstract}
Aloe dichotoma (Quiver tree) occurs in the arid regions of Namaqualand and Bushman land in South Africa, and in arid regions of southern Namibia. The Quiver trees are not only threatened by agricultural expansion, overgrazing, and mining; but also by climate changes and droughts. Previous studies show that Quiver trees are very sensitive to environmental changes, and do not respond well to extreme hot and dry conditions. This study investigates the current status of the Quiver tree within its existing environment, and also assesses the projected future changes of the Quiver tree habitat under different climatic scenarios. It provided evidence regarding the importance of the study to understanding the climate change impacts on the Quiver tree and its geographical response to climate changes.
\end{abstract}

\section{Keywords}

Climate Change, Conservation, Quiver Tree, Aloe Dichotoma, Karoo, Species Distribution, Arid Region, Namibia, South Africa

\section{Introduction and Background}

As the recent debates on climate change continues over the Anthropocene hypothesis on whether human activities and has a global impact on the Earth's atmosphere and geological processes [1], and whether the Antarctic ice are increasing or decreasing [2], there is no doubt that we as humans have forever changed the planet Earth and its ecosystem. This makes conservation and management of our ecosystem more difficult as not only we face prolonged droughts in Africa; we also have problems of land transformation and deforestation. Even a few degrees increase in temperature and a few millimeters of decrease in rainfall could cause a decline in the biodiversity of plants and animals in the arid regions [3] [4].

Aloe dichotoma (common name Quiver tree) occurs in the arid regions of Namaqualand and Bushman land in South Africa, and in arid regions of southern Namibia (Figure 1). This tree belongs to the genus Aloe and family Asphodelaceae, formerly Liliaceae [5]. The Quiver tree has succulent leaf and stem, and this succulent tree species lives in dry rocky areas and can grow quite rapidly under the right conditions. A. dichotoma has an av- 
erage life span that is estimated between a hundred and two hundred and fifty years [6] [7].

Due to the fact that the succulent plants has special water-storing tissue which makes part of the plant fleshy, therefore succulents are able to survive long periods of drought conditions [5]. The Quiver tree can grow up to 9 meters tall, and it has a 200 year life span (Figure 2). It is a base species within its distribution [9], and is adapted to survive very dry conditions and stores water in its trunk, branches and leaves [10].

The Quiver tree is essential to the local ecosystem and environment, because it is a source of moisture for a wide variety of mammals, birds and insects. Foden's [8] detailed research of the demographic data of the Quiver trees demonstrates that negligible recruitment has occurred in some populations for 50 years, and the effects of non-climatic variables, such as seed availability, herbivory, competition, and fungal pathogens, are very small. In this paper, we assess the current status of the Quiver tree within its existing environment, and also assess the projected future changes of the Quiver tree under different climatic scenarios.

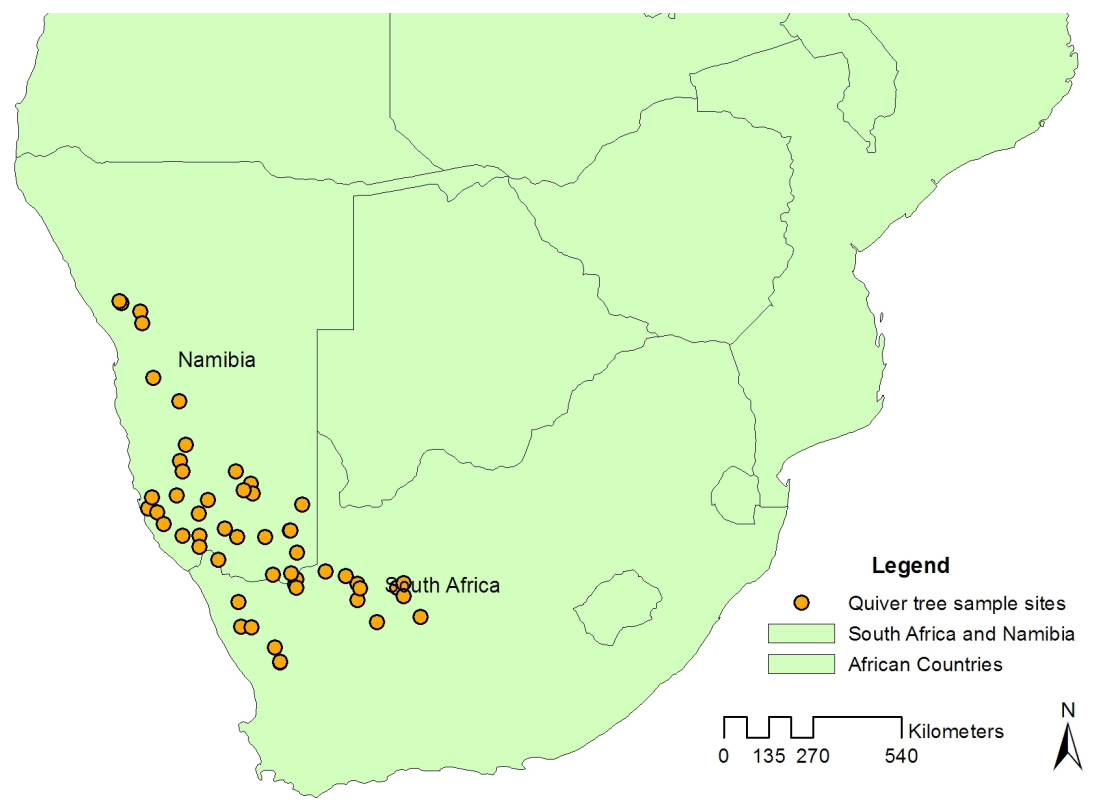

Figure 1. Quiver tree sample sites in Namibia and South Africa.

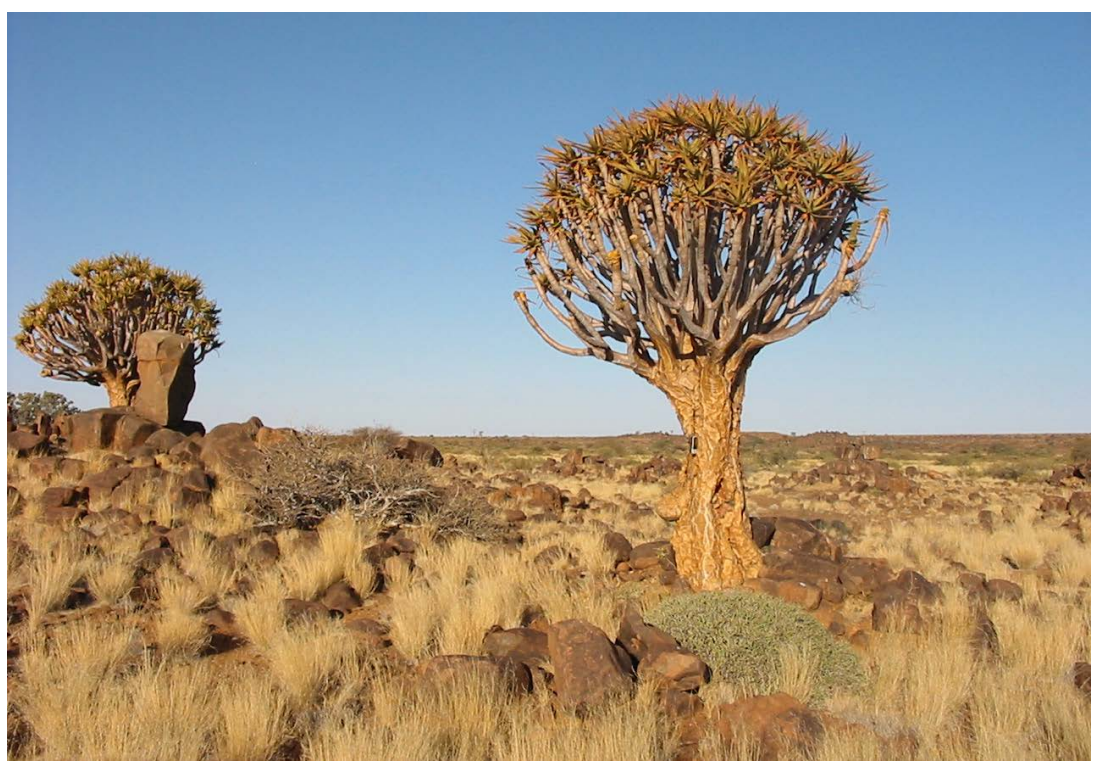

Figure 2. Quiver trees in Namibia 2008 [8]. 


\section{Present Status of Quiver Trees}

Presently, the conservation of Quiver trees is not only threatened by agricultural expansion, overgrazing, and mining; but also by climate changes and droughts [8]. Previous observations show that Quiver trees are very sensitive to environmental changes, and do not respond well to extreme hot and dry conditions [11]. Therefore climate change is one of the major factors affecting the existence of Quiver trees and the Quiver tree would be affected by long term climatic changes. The Quiver tree can provide a good indication of long term climate changes in the arid regions [8] [3].

As one can observe from Figure 3 the Quiver tree niche is limited by the biome regions, namely it exists only in Nama-Karoo and Succulent-Karoo regions [12] [13]. These ecological biomes itself are consisted of the vegetations living within a region, and therefore the biomes are subject to climate change impacts as well. However, examining the study area, it is highly unlikely for the Quiver tree to spread to Desert and Savanna regions.

\section{Climate Data and Analysis}

MPI-ESM-MR model from the Max Planck Institute for Meteorology was selected in this study, based on it proved to be a good Global Climate Model by comparison to others [14]. The MPI-ESM is a comprehensive Earth-System Model, and it consists of component models for the ocean, the atmosphere, and the land surface [15]. It is a fairly conservative model and as such was seen to be well suited for predictions of Southern African climate, with its inherent regions of dryness and wetness.

In this study we used RCP2.6 and RCP8.5 as comparative future scenarios, for future time period 2061-2080 [16]. Representative Concentration Pathways (RCPs) are greenhouse gas concentration trajectories adopted by the Intergovernmental Panel on Climate Change for its fifth Assessment Report in 2014 [17]. The RCP are named after a possible range of radiative forcing values in the year 2100 relative to pre-industrial values, +2.6 and $+8.5 \mathrm{~W} / \mathrm{m}^{2}$, respectively. RCP 2.6 assumes that global annual emissions measured in $\mathrm{CO}_{2}$-equivalents peak between 2010-2020 with emissions declining after, and RCP 8.5 assumes emissions continues to rise throughout the 21st century [17]. Obviously, RCP2.6 is a good but unlikely future scenario, and RCP8.5 is a more realistic future scenario based on the present human activity.

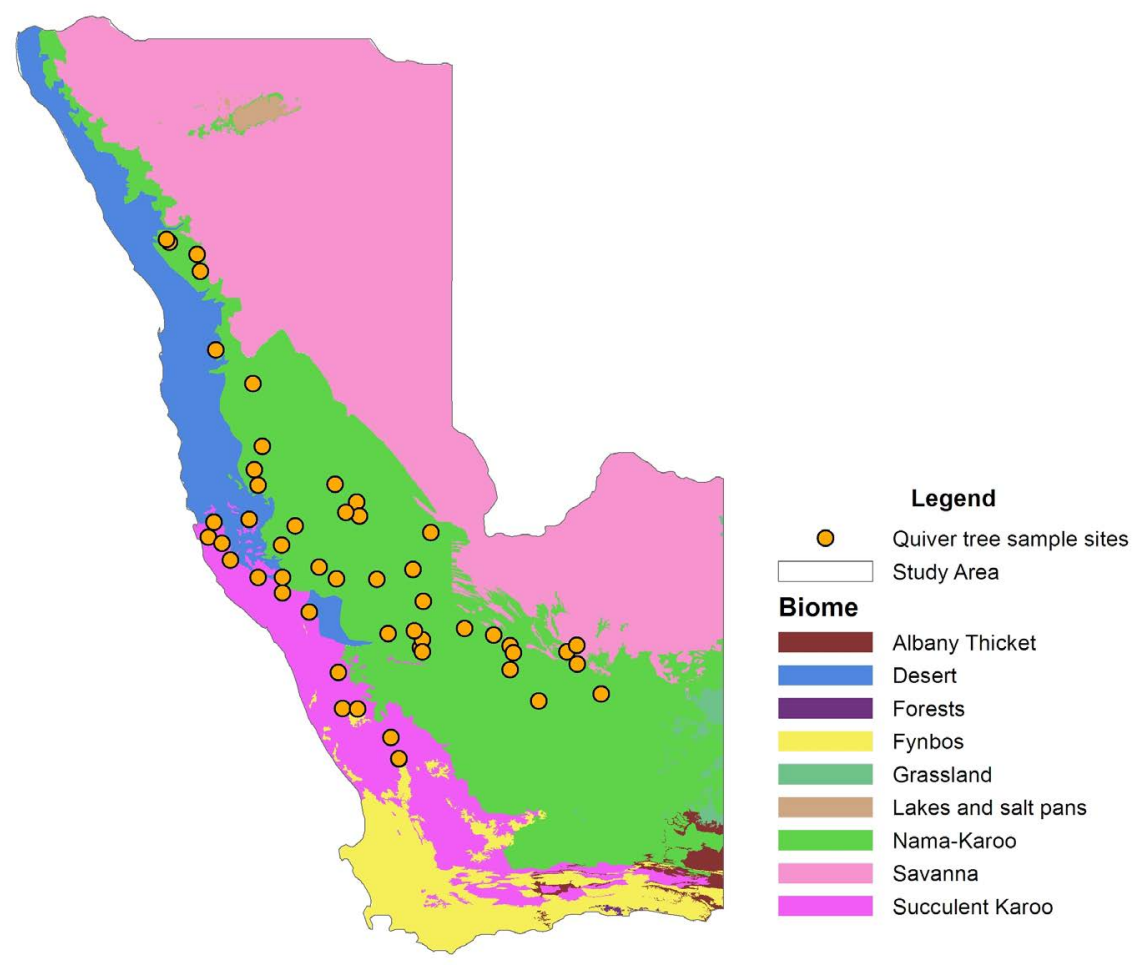

Figure 3. Ecological biomes in the Quiver tree study area. 
In order to examine the distribution and relationship between the Quiver tree and the climatic variables, the distributions are modelled to show the climatic niche of the Quiver trees. Species distribution models are used to estimate the relationship between the Quiver tree records at sample sites and the environmental and spatial characteristics of those sample sites [18], which in this case are the climatic variables. The species distribution model used in this study is MaxEnt [19]. MaxEnt applies Bayesian methods to estimate the potential geographic distribution of species by finding the probability distribution of maximum entropy and is an effective method for modelling species distributions from presence-only data [19]-[21].

The conventional Bayesian risk criterion is based on the quadratic loss function and use of a conjugate family Guo [22], and the Maximum Entropy modelling is an important Bayesian inference, which is established by different risk criterion. Maxent is a Bayesian approach by which the species probability distribution is statistically estimated by searching the family of probability distributions under the maximum entropy criterion subject to environmental constraints.

Gibbs sampling is a statistical algorithm used by Bayesian inference, which is used in Maxent. The Gibbs family $\left\{q_{\lambda}(x), \lambda \in \mathrm{L}\right\}$, where

$$
q_{\lambda}(x)=\frac{1}{Z_{\lambda}(x)} \exp \left(\sum_{i=1}^{m} \lambda_{i} f_{i}(x)\right)
$$

with $\lambda_{i}=\left(\lambda_{1}, \lambda_{2}, \cdots, \lambda_{m}\right)$ as the weight vector, and $\lambda_{i}$ being the weight parameters, $L$ being the $m$-dimensional space, and $f_{i}(x)$ representing species $i$ 's probability distribution, $Z_{\lambda}(x)$ being the normalized constant. Note that each element $x$ is a pixel of the investigated area. These probabilities $f_{i}(x)$ represent relative suitability of the environmental conditions in each pixel [19]-[21].

The environmental layers or the climate variables used in the modelling are the nineteen bioclimatic variables, and also altitude as a limiting variable. BIOCLIM is a bioclimatic prediction system which uses bioclimatic parameters, derived from mean monthly climate estimates, to approximate the energy and water balances, at a given location [23] [24]. The variables are: BIO1 = Annual Mean Temperature, BIO2 = Mean Diurnal Range, BIO3 = Isothermality, BIO4 $=$ Temperature Seasonality, BIO5 $=$ Maximum Temperature of Warmest Month, BIO6 $=$ Minimum Temperature of Coldest Month, BIO7 $=$ Temperature Annual Range, BIO8 $=$ Mean Temperature of Wettest Quarter, BIO9 = Mean Temperature of Driest Quarter, BIO10 = Mean Temperature of Warmest Quarter, BIO11 = Mean Temperature of Coldest Quarter, BIO12 $=$ Annual Precipitation, BIO13 $=$ Precipitation of Wettest Month, BIO14 = Precipitation of Driest Month, BIO15 = Precipitation Seasonality, BIO16 = Precipitation of Wettest Quarter, BIO17 = Precipitation of Driest Quarter, BIO18 = Precipitation of Warmest Quarter, BIO19 = Precipitation of Coldest Quarter, and also altitude as a limiting factor.

\section{Projected Future Changes in Quiver Tree Distribution}

Examining the change maps in Figure 4 and Figure 5, one can clearly see that there is a visible difference between niche changes under RCP2.6 climate scenario, and under the RCP8.5 climate scenario. A niche defines the way in which a species fits into an ecosystem and ecological community, and it is modelled by the environmental variables [25]. Climate factors are the main environmental variables which contribute to the determination of Quiver tree niche, because of the semi-arid environment of South Africa.

Table 1 examines the climate variable percentage contributions to the MaxEnt model. As one can conclude from the table, the Annual Precipitation (20.3453\%), Minimum Temperature of Coldest Month (19.905\%), Precipitation of Warmest Quarter (17.186\%), and the Precipitation of Wettest Quarter (12.031\%); are the climate variables of the highest percentage contributions to the model [26] [27]. Therefore the Quiver tree is shown to be very sensitive to long term rainfall, and temperature and rainfall extremes.

In the RCP2.6 scenario (Figure 4), most of the existing climatic niche has survived, with some loss of habitat in the Nama-Karoo region, and also showing a very positive possible expansion northwards. This is a good and positive sign for the Quiver tree, though this scenario is highly unlikely, since technological developments will not stop at the year 2020.

In the RCP8.5 scenario (Figure 5), it is evident the Quiver tree are losing most of its natural niche area, and though it is showing a positive expansion, but there is no certainty in habitat shifts. And it is highly unlikely for the Quiver tree to move into the Savanna biome instead. 


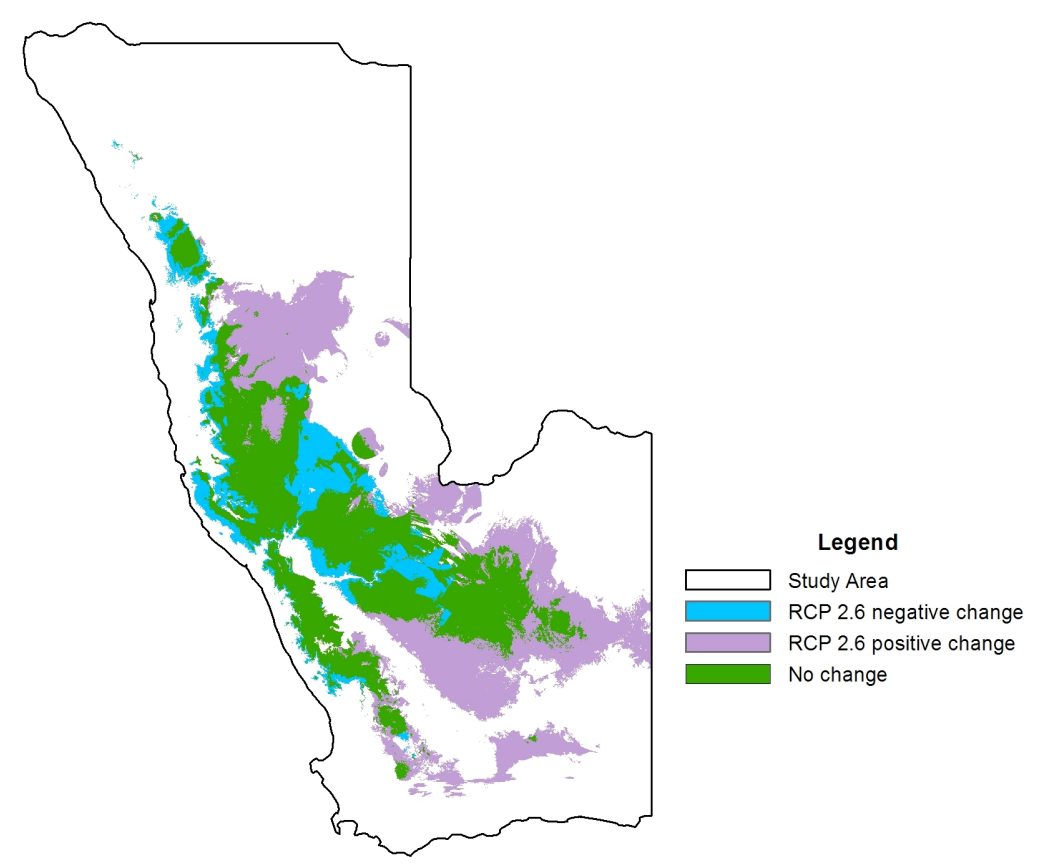

Figure 4. Projected future change in geographic range of Quiver tree under RCP 2.6.

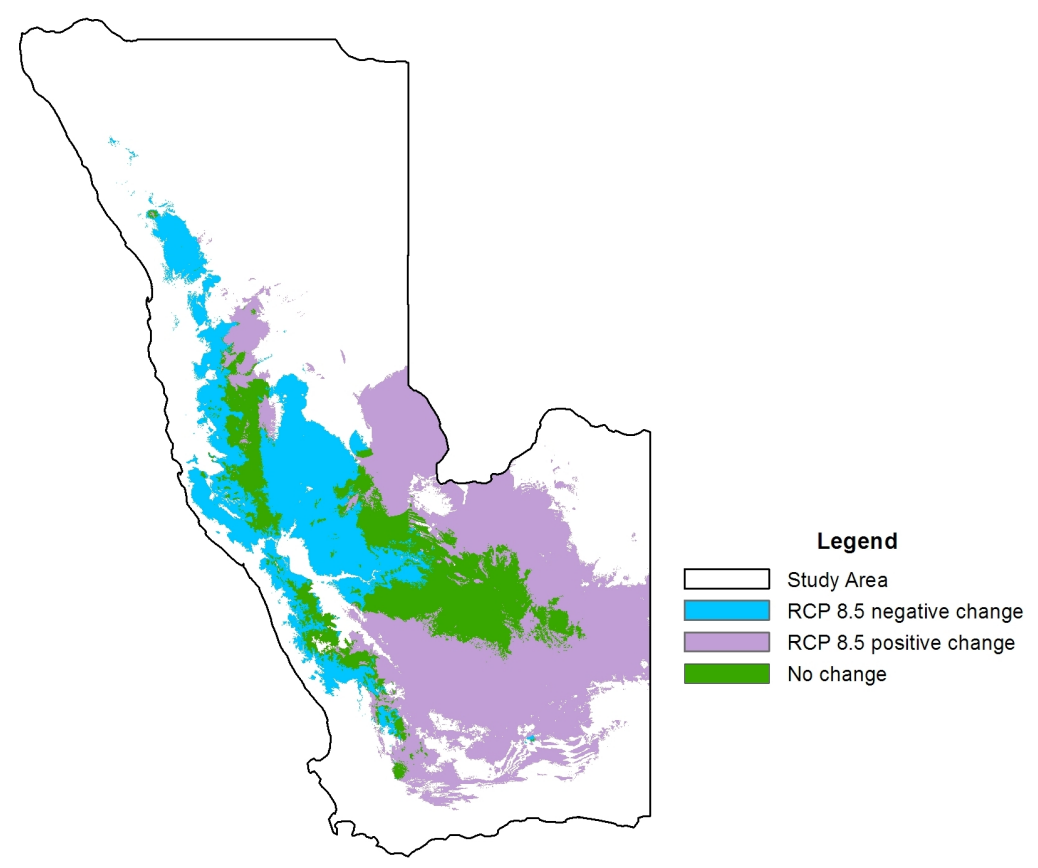

Figure 5. Projected future change in geographic range of Quiver tree under RCP 8.5.

As devastating as the RCP8.5 scenario is on Quiver tree survival, however due to human induced climate changes this is a more plausible scenario, given our current technological developments and current ecological changes. These results are very important in learning Quiver tree responses towards different climatic conditions in the future.

\section{Interpretation and Conclusion}

The responses of species to climate change are complicated sometimes by cumulative effects, but phenological 
Table 1. Climate variable percentage contributions to MaxEnt model.

\begin{tabular}{|c|c|}
\hline Variable names & Percentage contribution \\
\hline 1. BIO1 = Annual Mean Temperature & 0.6675 \\
\hline 2. $\mathrm{BIO} 2=$ Mean Diurnal Range & 0.0643 \\
\hline 3. BIO3 = Isothermality & 4.215 \\
\hline 4. $\mathrm{BIO} 4=$ Temperature Seasonality & 1.1647 \\
\hline 5. BIO5 = Max Temperature of Warmest Month & 0.1469 \\
\hline 6. BIO6 = Min Temperature of Coldest Month & 19.905 \\
\hline 7. $\mathrm{BIO}$ = Temperature Annual Range & 0.9838 \\
\hline 8. BIO8 = Mean Temperature of Wettest Quarter & 0.6097 \\
\hline 9. BIO9 = Mean Temperature of Driest Quarter & 0.1418 \\
\hline 10. BIO10 = Mean Temperature of Warmest Quarter & 0 \\
\hline 11. BIO11 = Mean Temperature of Coldest Quarter & 0 \\
\hline 12. $\mathrm{BIO} 12=$ Annual Precipitation & 20.3453 \\
\hline 13. BIO13 = Precipitation of Wettest Month & 1.2153 \\
\hline 14. BIO14 = Precipitation of Driest Month & 9.6543 \\
\hline 15. BIO15 = Precipitation Seasonality & 1.9347 \\
\hline 16. BIO16 = Precipitation of Wettest Quarter & 12.031 \\
\hline 17. BIO17 = Precipitation of Driest Quarter & 0.772 \\
\hline 18. BIO18 = Precipitation of Warmest Quarter & 17.186 \\
\hline 19. BIO19 = Precipitation of Coldest Quarter & 1.0474 \\
\hline 20. Altitude & 7.9155 \\
\hline
\end{tabular}

and distributional shifts are the most common measureable appearances [10] [28] [29]. Recent climate change research have indicated that many plant species will become extinct by the year 2100 as a result of rapid changes in climatic conditions [4], and this could be the fate of the Quiver tree if climate changes are not kept in check by government policies. Foden [8] have found an increase in mortality rate and also that the degree of recruitment have also decreased in Aloe dichotoma over the last few years as a result of low precipitation and higher precipitation variability as a consequence of changes in climatic conditions. According to Jack [10] it is assumed that A. dichotoma recruits periodically during high rainfall years, depending on the regularity of the rainfall.

As this study has shown that the Quiver tree is very sensitive to long term rainfall, and temperature and rainfall extremes, and that the future projected climate scenarios can make a huge impact on its survival. Under the RCP2.6 scenario, the Quiver tree maintained most of its natural niche area, and has shown some reasonable expansion. However, under the RCP8.5 scenario, the Quiver tree not only loses most of its natural niche area, but shown also, it is highly unlikely to have a complete range shift, therefore it might face threats of extinction, due to future climate changes and human activities. This study provided evidence on the importance of understanding the climate change impacts on the Quiver tree and its geographical response to climate changes.

\section{Acknowledgements}

Sincere thanks to the South African National Biodiversity Institute (SANBI) for their support of the Aloe Project, and to the CGIAR Research Program on Climate Change, Agriculture and Food Security (CCAFS) and WorldClim for providing the data. This research is supported financially by the National Research Foundation (NRF) of South Africa, NRF Funding Reference: IFR150206113775 Grant number: 96163. 


\section{References}

[1] Smith, B.D. and Zeder, M.A. (2013) The Onset of Anthropocene. Anthropocene, Elsevier, 4, 8-13. http://dx.doi.org/10.1016/j.ancene.2013.05.001

[2] NASA (2015) NASA Study shows Global Sea Ice Diminishing, Despite Antarctic Gains. www.nasa.gov/feature/goddard/nasa-study-mass-gains-of-antarctic-ice-sheet-greater-than-losses

[3] Guo, D., Guo, R., Cui, Y.H., Midgley, G.F., Altwegg, R. and Thiart, C. (2011) Climate Change Impact on Quiver Trees in Arid Namibia and South Africa. In: Blanco, J. and Kheradmand, H., Ed., Climate Change - Geophysical Foundations and Ecological Effects, InTech, 323-342. http://dx.doi.org/10.5772/23999

[4] Young, A.J., Guo, D., Desmet, P.G. and Midgley, G.F. (2016) Biodiversity and Climate Change: Risks to Dwarf Succulents in Southern Africa. Journal of Arid Environments, 129, 16-24. http://dx.doi.org/10.1016/j.jaridenv.2016.02.005

[5] Van Wyk, B.E. and Smith, G. (1996) Guide to the Aloes of South Africa. Briza Publications, Pretoria.

[6] Vogel, C. (1974) The Lifespan of the Kokerboom. Aloe, 12, 66-68.

[7] Kaleme, P.K. (2003) Regional Differences in the Long-Term Population Dynamics of a Succulent Tree Aloe dichoto$m a$ in the Semi-Arid Karoo, as Revealed by Repeat Photography. M.Sc. Thesis, University of Cape Town, Cape Town.

[8] Foden, W. (2002) A Demographic Study of Aloe Dichotoma in the Succulent Karoo: Are the Effects of Climate Change Already Apparent? M.Sc. Thesis, Percy FitzPatrick Institute of African Ornithology, Botany Department, University of Cape Town.

[9] Midgley, J.J., Cowling, R.M., Hendricks, H., Desemet, P.G., Esler, K. and Rundel, P. (1997) Population Ecology of Tree Succulents (Aloe and Pachypodium) in the Arid Western Cape: Decline of Keystone Species. Biodiversity and Conservation, 6, 869-876. http://dx.doi.org/10.1023/B:BIOC.0000010407.65612.27

[10] Jack, S.L. (2011) Revisiting Aloe dichotoma's Suitability as Indicator of Climate Change in Southern Africa. M.Sc. Thesis, University of Cape Town, Cape Town.

[11] Midgley, G.F., Altwegg, R., Guo, D. and Merow, C. (2009) Are Quiver Trees a Sentinel for Climate Change in Arid Southern Africa? South African National Biodiversity Institute.

[12] Rutherford, M.C. (1997) Categorization of biomes. In: Cowling, R.M., Richardson, D.M. and Pierce, S.M., Ed., Vegetation of southern Africa, Cambridge University Press, Cambridge, 91-98.

[13] Mucina, L. and Rutherford, M.C., Eds. (2006) The Vegetation of South Africa, Lesotho and Swaziland. Strelitzia 19, South African National Biodiversity Institute, Pretoria.

[14] Connolley, W.M. and Bracegirdle, T.J. (2007) An Antarctic Assessment of IPCC AR4 Coupled Models. Geophysical Research Letters, 10, L22505. http://dx.doi.org/10.1029/2007gl031648

[15] Max-Planck-Institut für Meteorologie (2015) MPI-ESM. https://verc.enes.org/models/earthsystem-models/mpi-m/mpi-esm

[16] Hijmans, R.J., Cameron, S.E., Parra, J.L., Jones P.G. and Jarvis, A. (2005) Very High Resolution Interpolated Climate Surfaces for Global Land Areas. International Journal of Climatology, 25, 1965-1978. http://dx.doi.org/10.1002/joc.1276

[17] Flato, G., Marotzke, J., Abiodun, B., Braconnot, P., Chou, S.C., Collins, W., Cox, P., Driouech, F., Emori, S., Eyring, V., Forest, C., Gleckler, P., Guilyardi, E., Jakob, C., Kattsov, V., Reason, C. and Rummukainen, M. (2013) Evaluation of Climate Models. In: Stocker, T.F., Qin, D., Plattner, G.K., Tignor, M., Allen, S.K., Boschung, J., Nauels, A., Xia, Y., Bex, V. and Midgley, P.M., Eds., Climate Change 2013: The Physical Science Basis, Contribution of Working Group I to the Fifth Assessment Report of the Intergovernmental Panel on Climate Change, Cambridge University Press, Cambridge, United Kingdom and New York, NY, USA.

[18] Franklin, J. (2009) Mapping Species Distributions: Spatial Inference and Prediction. Cambridge University Press, Cambridge, UK.

[19] Phillips, S.J., Anderson, R.P. and Schapire, R.E. (2006) Maximum Entropy Modeling of Species Geographic Distributions. Ecological Modelling, 190, 231-259. http://dx.doi.org/10.1016/j.ecolmodel.2005.03.026

[20] Phillips, S.J., Dudík, M. and Schapire, R.E. (2004) A Maximum Entropy Approach to Species Distribution Modeling. Proceedings of the Twenty-First International Conference on Machine Learning, 655-662. http://dx.doi.org/10.1145/1015330.1015412

[21] Elith, J., Phillips, S.J., Hastie, T., Dudík, M., Chee, Y.E. and Yates, C.J. (2011) A Statistical Explanation of MaxEnt for Ecologists. Diversity and Distributions, 17, 43-57. http://dx.doi.org/10.1111/j.1472-4642.2010.00725.x

[22] Guo, R. (2010) Bayesian Reliability Modelling. In: Lovric, M., Ed., International Encyclopedia of Statistical Science, Springer-Verlag, Berlin, 104-106.

[23] Fenner School (2016) ANUCLIM. http://fennerschool.anu.edu.au/research/products/anuclim-vrsn-61 
[24] Nix, H. (1986) Abiogeographic Analysis of Australian Elapid Snakes. In: Longmore, R. Ed., Snakes: Atlas of Elapid snakes of Australia, Bureau of Flora and Fauna, Canberra, 4-10.

[25] Moyle, P. (2012) Niche and Habitat. Marine Conservation. http://marinebio.org/Oceans/Conservation/Moyle/ch7.asp

[26] McLeish, M., Guo, D. van Noort, S. and Midgley, G.F. (2011) Life on the Edge: Rare and Restricted Episodes of a Pan-Tropical Mutualism Adapting to Drier Climates. New Phytologist, 191, 210-222. http://dx.doi.org/10.1111/j.1469-8137.2011.03683.x

[27] Guo, D., Zietsman, G. and Hockey, P.A.R. (2016) Climate Change Impacts on the Common Swift in South Africa. Journal of Environmental Science and Development, 7, 306-311.

[28] Parmesan, C. (2006) Ecological and Evolutionary Responses to Recent Climate Change. Annual Review of Ecology, Evolution and Systematics, 37, 637-669. http://dx.doi.org/10.1146/annurev.ecolsys.37.091305.110100

[29] Walther, G.R. (2010) Community and Ecosystem Responses to Recent Climate Change. Philosophical Transactions of the Royal Society, 365, 2019-2024. http://dx.doi.org/10.1098/rstb.2010.0021

\section{Submit or recommend next manuscript to SCIRP and we will provide best service for you:}

Accepting pre-submission inquiries through Email, Facebook, LinkedIn, Twitter, etc. A wide selection of journals (inclusive of 9 subjects, more than 200 journals)

Providing 24-hour high-quality service

User-friendly online submission system

Fair and swift peer-review system

Efficient typesetting and proofreading procedure

Display of the result of downloads and visits, as well as the number of cited articles

Maximum dissemination of your research work

Submit your manuscript at: http://papersubmission.scirp.org/ 